\title{
Sistem Kontrol dan Monitoring Tanaman Hidroponik Aeroponik Berbasis Internet of Things
}

\author{
Putu Denanta Bayuguna Perteka, I Nyoman Piarsa, Kadek Suar Wibawa \\ Universitas Udayana, Teknologi Informasi, Jimbaran \\ e-mail: putubayuguna@gmail.com, manpits@unud.ac.id, suar wibawa@unud.ac.id
}

\begin{abstract}
Abstrak
Pesatnya pertambahan penduduk berdampak pada sektor pertanian sebagai akibat dari pengalihan lahan pertanian. Pengalihan ini berdampak juga pada persediaan bahan pangan dan kerusakan ekosistem. Untuk menghadapi permasalahan tersebut, perlu diupayakan penggunaan teknologi sebagai sebuah solusi di era digitalisasi. Penelitian ini memadukan tanaman hidroponik dengan bantuan teknologi Internet of Things (IoT) menggunakan teknik penanaman Aeroponik. Aeroponik merupakan teknik dalam penanaman hidroponik yang memberikan larutan nutrisi dalam bentuk kabut langsung menuju ke akar, sehingga tanaman lebih mudah menyerap nutrisi. Perancangan perangkat loT menggunakan mikrokontroler raspberry pi yang diinetgrasikan dengan mikrokontroler Arduino Mega sebagai pusat dalam menjalankan sensor pendukung seperti sensor water level, ultrasonik, ph, tds, dan dht22. Aplikasi mobile android digunakan sebagai interface dalam kontrol dan monitoring perangkat oleh pengguna. Dari rancangan dan serangkaian uji coba pada sistem disimpulkan bahwa, rancangan sistem tanaman hidroponik aeroponik berbasis loT mampu melakukan monitoring dan controlling tanaman, serta otomatisasi dalam pencampuran nutrisi sesuai dengan kebutuhan tanaman.
\end{abstract}

Kata kunci: Internet of Things, Hidroponik, Aeroponik, Mikrokontroler, Android.

\begin{abstract}
The rapid growth of population has an impact on the agricultural sector as a result of the transfer of agricultural land for settlement. This diversion has an impact on food supplies and damage to ecosystems. To deal with these problems, it is necessary to make efforts to use technology as a solution in the era of digitalization. This research combines hydroponic plants with the help of Internet of Things (IOT) technology using Aeroponic planting techniques. Aeroponics is a technique in hydroponic cultivation that provides nutrient solutions in the form of mist directly to the roots, so that plants can more easily absorb nutrients. The design of the loT device uses a raspberry pi microcontroller integrated with the Arduino Mega microcontroller as the center for running supporting sensors such as water level, ultrasonic, $\mathrm{pH}$, tds, and $\mathrm{DH} 22$ sensors. From the design and a series of experiments on the system, it was concluded that the design of the loT-based aeroponic hydroponic system is capable of monitoring and controlling plants, as well as automation in mixing nutrients according to plant needs.
\end{abstract}

Keywords : Internet of Things, Hidroponik, Aeroponik, Microcontroller, Android.

\section{Pendahuluan}

Pertambahan penduduk yang sangat pesat saat ini mengakibatkan terjadinya pengalihan lahan pertanian menjadi permukiman penduduk. Hal ini berdampak pada pengurangan lahan pertanian untuk membudidayakan tanaman. Dalam jangka panjang, penyempitan lahan pertanian akan berdampak pada kelangkaan sumber pangan dan kerusakan ekosistem. Selain sebagai sumber pangan, fungsi utama suatu tanaman yaitu menghasilkan $\mathrm{O}_{2}$ (Oxygen) yang dibutuhkan setiap makhluk hidup untuk bernafas dan menyerap $\mathrm{CO}_{2}$ (Carbon Dioksida) yang dapat membahayakan makhluk hidup.

Mengingat pentingya peran tanaman dalam kelangsungan makhluk hidup, diperlukan inovasi-inovasi dalam pengembangan dalam sektor pertanian dengan memanfaatkan teknologi. Hal ini sejalan dengan tuntutan dalam Revolusi Industri 4.0. Revolusi Industri 4.0 yang ditandai dengan adanya digitalisasi dan komputerisasi telah merubah seluruh aspek produksi di industri 
dengan menggabungkan teknologi digital dengan industri konvensional [1]. Beberapa penelitian yang mengkaji perihal revolusi industri 4.0 dengan memanfaatkan teknologi Internet of Thing dalam sektor pertanian untuk mengatasi permasalahan lahan pertanian menggunakan teknik penanaman hidroponik yang digabungkan dengan perangkat loT (Internet of Things), diantaranya penerapan sistem hidroponik dibuat menggunakan mikrokontroler raspberry pi dan mikrokontroler wifi esp8266 untuk terhubung ke jaringan internet yang memungkinkan pengguna dalam memanajemen dan monitoring tanaman melalu aplikasi berbasis web [2]. Penelitian lainnya mengkaji rancangan bangun sistem dibuat menggunakan mikrokontroler sebagai pengatur kerja dari sistem tanam aeroponik yang memberikan nutrisi dalam bentuk kabut menuju langsung ke akar sehingga tanaman dapat lebih mudah dalam menyerap nutrisi [3], sedangkan penelitian lainnya berupa pengembangan sistem otomatisasi dalam pencampuran nutrisi dengan menggunakan sensor tds dan ph dalam pembacaan larutan nutrisi yang akan diberikan ke tanaman sehingga pemberian nutrisi dapat dilakukan secara maksimal sesuai dengan kebutuhan tanaman yang dapat diatur melalui aplikasi mobile berbasis android [4]. Pada penelitian yang telah dilakukan sebelumnya masih memiliki beberapa kelemahan yaitu seperti tidak adanya indikator dalam pembacaan kondisi pada perangkat, perintah dalam pemberian nutrisi pada tanaman masih dilakukan secara manual melalui aplikasi android, dan kurang optimal dalam implementasi sistem yang belum dinamis dalam memanajemen tanaman dan hanya memfokuskan pada 1 jenis tanaman.

Hidroponik merupakan cara tanam tanpa memerlukan lahan yang luas sehingga sangat cocok dibudidayakan pada daerah-daerah perkotaan. Salah satu teknik dalam penanaman hidroponik adalah dengan sistem aeroponik. Akan tetapi, penanaman hidroponik memiliki kelemahan antara lain diperlukan lingkungan yang sangat terkontrol untuk menjaga kesegaran tanaman dan mengindari penurunan hasil panen. Dengan kesibukan pelaku pertanian di daerah perkotaan, penerapan sistem penanaman hidropinik konvensional sulit dilakukan. Dengan demikian diperlukan suatu solusi untuk mengontrol kondisi tanaman scara otomatis sesuai dengan kebutuhan.

Penelitian ini dilakukan untuk memberikan solusi alternative dalam budidaya tanaman hidroponik dengan memanfaatkan teknologi berbasis loT yang dapat membantu dalam controlling dan monitoring tanaman secara otomatis sehingga dapat membantu masyarakat luas dalam membudidayakan tanaman hidroponik. Sistem yang dibuat mengintegrasikan antara perangkat loT dengan smartphone android yang berfungsi sebagai controlling dan monitoring tanaman.

\section{Metodologi Penelitian}

Penelitian ini dilaksanakan melalui serangkaian proses dimulai dari analisis kebutuhan, pengumpulan data melalui studi pustaka, melakukan perancangan, dan uji coba rancangan. Berikut dipaparkan gambaran pengembangan system yang dilakukan dalam proses perancangan dan ujicoba sistem kontrol dan monitoring tanaman hidroponik aeroponik berbasis loT.

\subsection{Gambaran Umum Sistem}

Gambaran umum digunakan untuk memperlihatkan gambaran secara umum dari sistem yang dibuat disajikan pada Gambar 1 . 


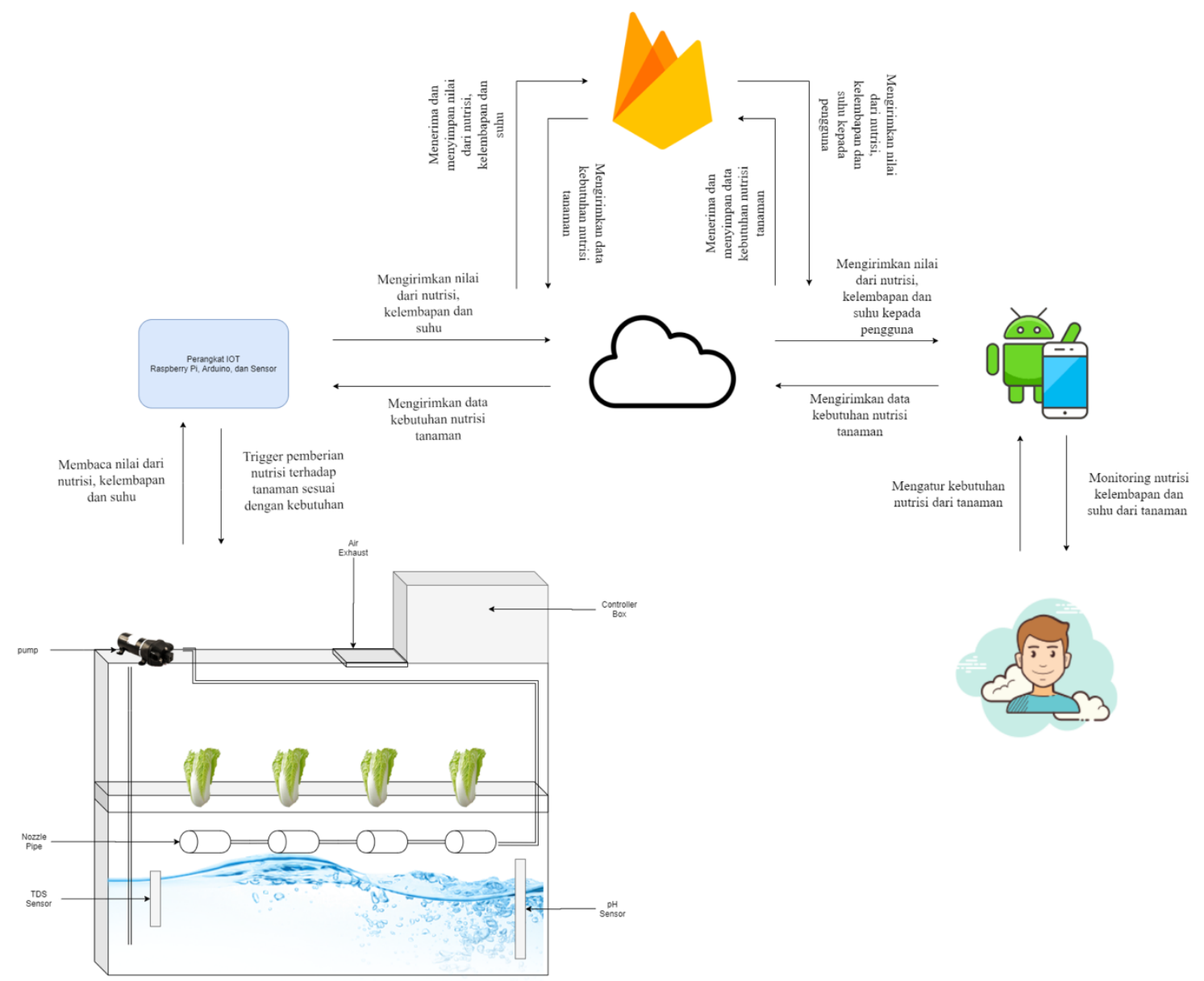

Gambar 1. Gambaran umum sistem

Gambaran umum sistem dari penelitian yang dilakukan yaitu pengguna mampu untuk mengaskses menggunakan aplikasi android untuk melakukan pengaturan tentang kondisi tanaman yang akan ditanam dan monitoring kondisi perangkat. Aplikasi android di integrasikan dengan cloud firebase database sebagai media penyimpanan data yang nantinya dapat digunakan untuk mengambil dan mengelola data dalam penanaman tanaman hidroponik. Perangkat IoT yang di integrasikan dengan cloud firebase database digunakan untuk pembacaan kondisi tanaman dalam memanajemen tanaman dan menyimpan informasi setiap kondisi perangkat untuk digunakan oleh pengguna dalam memanajemen perangkat.

\subsection{Diagram Use Case}

Diagram use case memperlihatkan sistem dari sudut pandang pengguna untuk mempermudah dalam pemahaman dari penelitian yang dibuat. Diagram use case disajikan pada Gambar 2. 


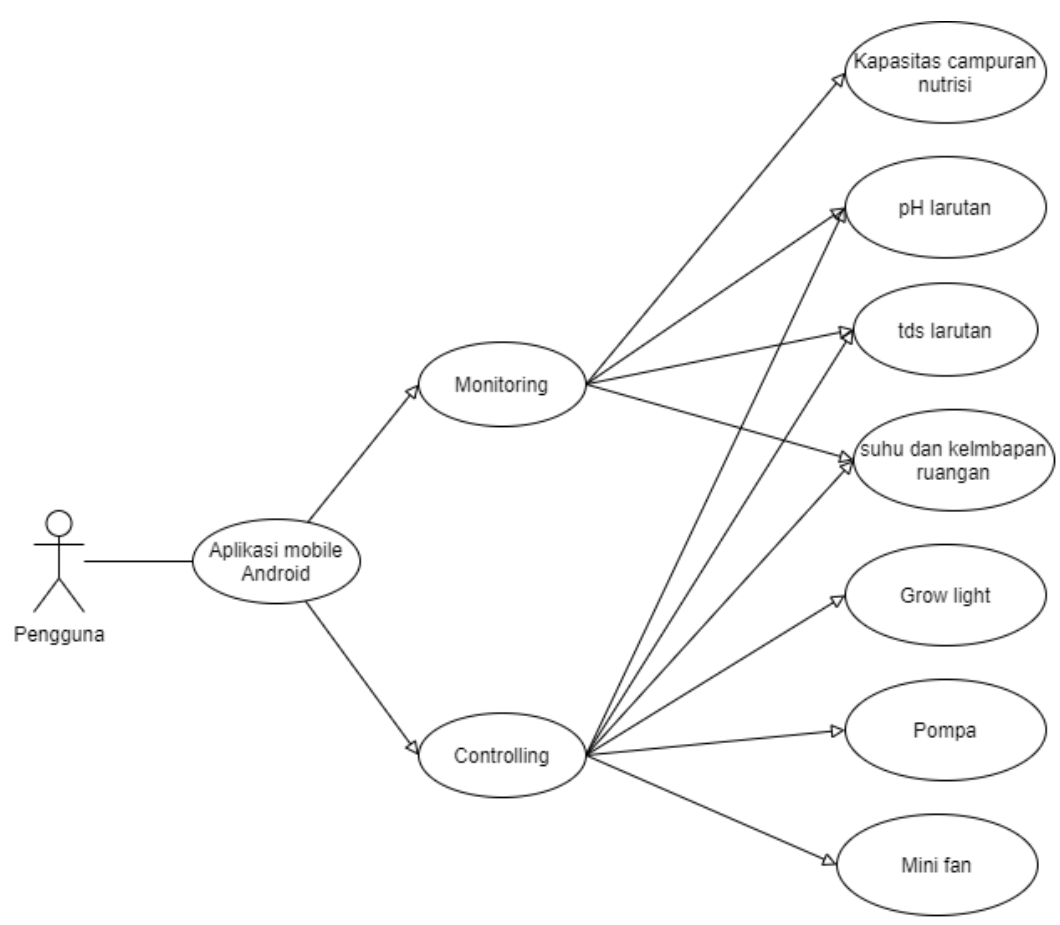

Gambar 2. Diagram use case

Pengguna menggunakan aplikasi mobile berbasis android dalam mengakses sistem monitoring dan controlling yang dihubungkan dengan setiap perangkat pendukung yang ada pada sistem seperti monitoring kapasitas campuran nutrisi, ph larutan, tds/ppm larutan, suhu dan kelembaban. Pengguna juga dapat melakukan controlling perangkat seperti memberikan batasan nilai pada ph larutan, tds/ppm larutan, suhu ruangan, menghidupkan dan mematikan grow light, pompa dan mini fan.

\subsection{Data Flow Diagram}

Data Flow Diagram merupakan aliran data yang menggambarkan masukan dan keluran setiap proses dari sistem yang dibuat. Aliran data disajikan pada Gambar 3.

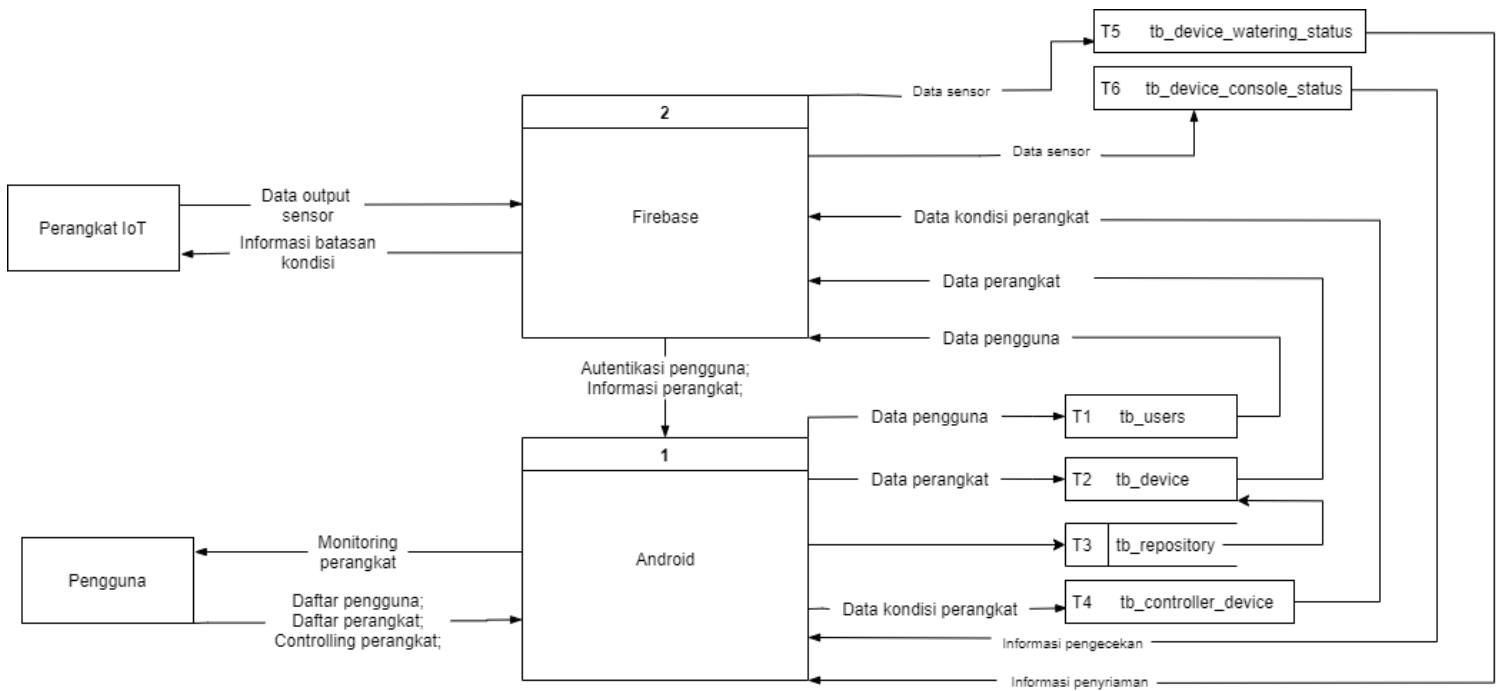

Gambar 3. Data Flow Diagram level 1

Data Flow Diagram level 1 memperlihatkan setiap proses yang ada pada sistem secara lebih rinci yang membentuk aliran data dan data store. Proses-proses tersebut meliputi proses firebase dan android terhubung dengan entitas pengguna dan perangkat loT yang 
menghasilkan data store seperti tb_users,, tb_device, tb_controller_device, tb_device_watering_status, tb_device_console_status, dan tb_repository.

\subsection{Diagram Skematik}

Diagram skematik memperlihatkan rangkaian elektronik yang menghubungkan antara mikrokontroler dengan sensor dan perangkat pendukung lainnya. Rangkain elektronik disajikan pada Gambar 4.
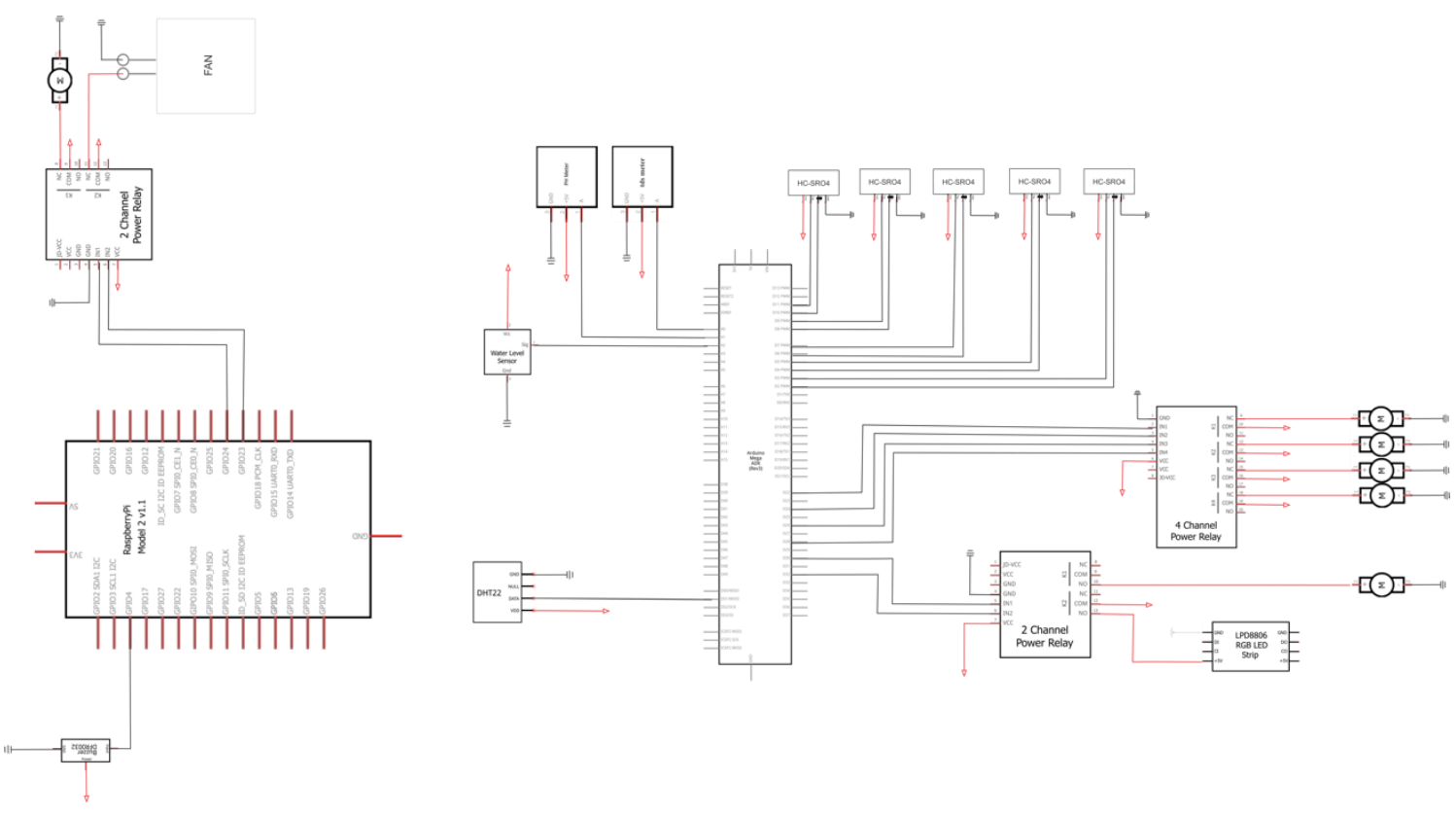

Gambar 4. Diagram skematik

Setiap sensor dan perangkat dihubungkan pada masing-masing pin yang ada pada mikrokontroler untuk membaca dan mengirimkan perintah. Mikrokontroler Arduino mega dihubungkan dengan 5 buah sensor ultrasonik, 1 buah sensor dht22, 1 sensor ph, 1 sensor tds, 1 buah sensor water level, 1 buah relay 4 modul yang terhubung dengan 4 buah pompa submersible, dan 1 buah relay 2 modul yang terhubung dengan 1 buah pompa submersible dan 1 buah led grow light. Sedangkan untuk mikrokontroler raspberry pi dihubungkan dengan 1 buah buzzer dan 1 buah relay 2 modul yang terhubung dengan 1 buah pompa hidropressure dan 1 buah mini fan.

\subsection{Conceptual Data Model}

Conceptual data model adalah skema konseptual yang memperlihatkan kandungan informasi yang ada pada basis data yang dibuat dalam sistem. Skema basis data disajikan pada Gambar 5. 


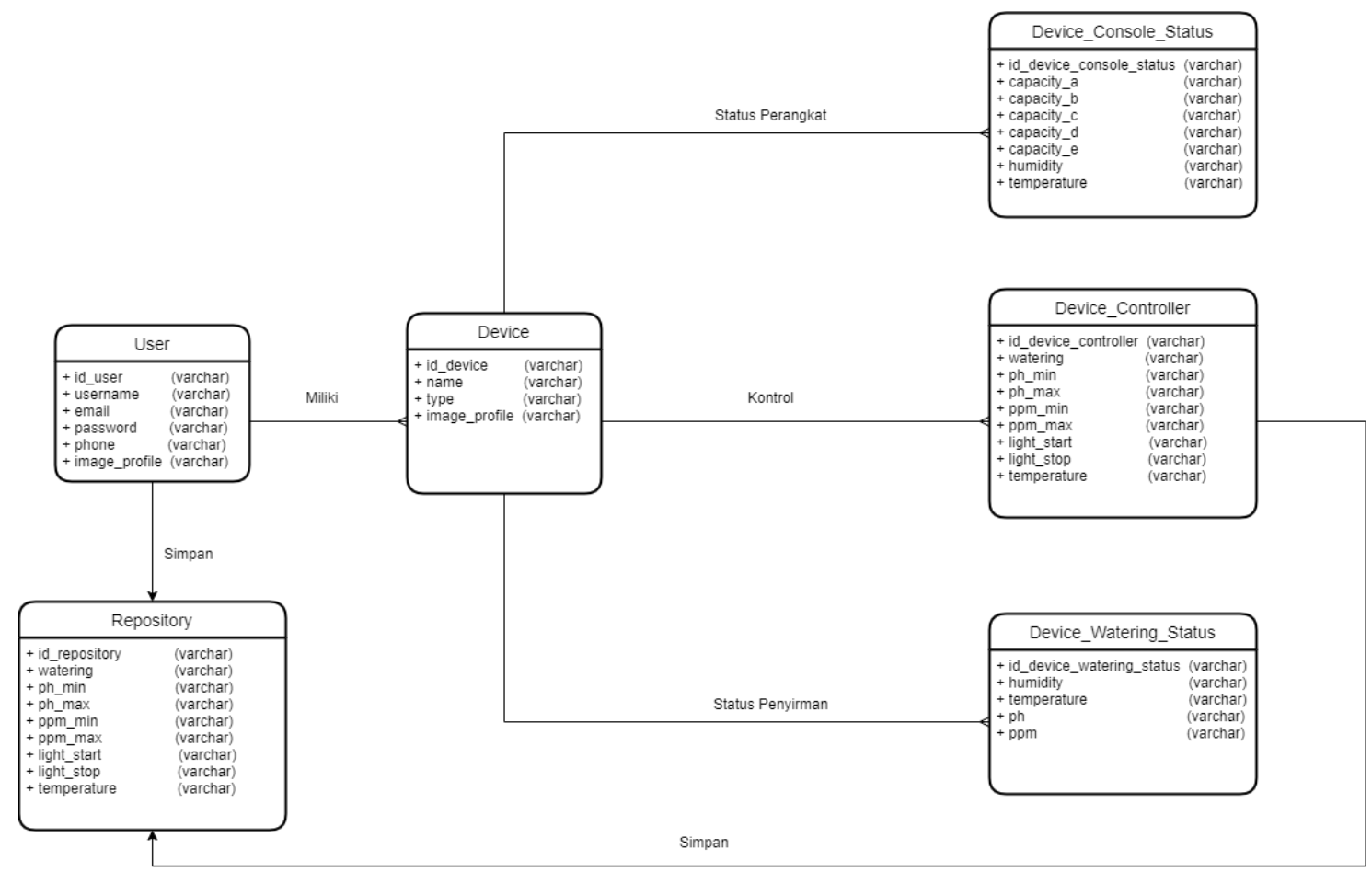

Gambar 5. Conceptual data model

Setiap informasi yang didapatkan dalam sistem disimpan dan dikelola untuk digunakan kembali dalam monitoring dan controlling perangkat loT. Informasi yang disimpan seperti informasi pengguna, perangkat, status perangkat, kontrol perangkat, dan status penyiraman. Tabel user diperuntukan untuk menyimpan data diri pengguna yang dapat digunakan dalam melakukan login ke dalam aplikasi. Tabel device diperuntukan untuk menyimpan perangkat yang dimiliki oleh pengguna. Tabel device console status diperuntukan untuk menyimpan pembaharuan data yang dikirim oleh perangkat untuk digunakan dalam melakukan monitoring perangkat oleh pengguna. Tabel device controller diperuntukan untuk menyimpan pengaturan dari kondisi yang digunakan dalam melakukan penanaman. Tabel watering status diperuntukan untuk menyimpan data setiap dilakukannya penyirman agar pengguna mampu untuk memonitoring nutrisi yang diterima oleh tanaman, sedangkan untuk tabel repository diperuntukan untuk menyimpan kondisi perangkat yang dimiliki agar dapat digunakan kembali oleh pengguna jika menanam tanaman yang sama.

\section{Kajian Pustaka}

Penelitian ini memiliki beberapa kajian pustaka yang berisi tentang konsep dan teori yang berkaitan dalam penelitian yang dilakukan bersumber dari buku dan jurnal.

\subsection{Internet of Things}

Internet of Things atau dikenal juga dengan singkatan loT, merupakan sebuah konsep yang bertujuan untuk memperluas manfaat dari konektivitas internet yang tersambung secara terus-menerus. IoT memungkinkan untuk pengguna dalam mengelola perangkat listrik yang digabungkan dengan internet agar mampu melakukan komunikasi dan bertukar informasi antar komputer selama perangkat terhubung dengan internet [5].

\subsection{Hidroponik}

Hidroponik merupakan budidaya tanaman dengan memanfaatkan air tanpa menggunakan media tanah dengan menekankan pada pemenuhan nutrisi bagi tanaman tanpa menggunakan lahan yang luas. 


\subsection{Fertigasi Sistem Hidroponik}

Fertigasi merupakan istilah pemberian nutrisi dalam larutan pada sistem tanam hidroponik yang dapat diatur sesuai dengan kebutuhan tanaman. Terdapat beberapa faktor dalam fertigasi sistem tanaman hidroponik agar kebutuhan dari tanaman dapat terpenuhi secara maksimal yaitu seperti kualitas air, Electircal Conductivity (EC), pH, dan unsur hara tanaman. Fertigasi memiliki beberapa manfaat yaitu seperti peningkatan dalam penyerapan nutrisi, pengurangan pupuk, bahan kimia, dan konsumsi air yang dibutuhkan, meminilalisir risiko tertularnya penyakit, mengurangi biaya operasional, mengatur frekuensi pemberian larutan sesuai dengan kebutuhan, meningkatkan produktivitas dan kualitas serta meningkatkan efisiensi waktu penanaman. Selain itu fertigasi juga memiliki kelemahan seperti konsentrasi larutan menurun, penggunaan pupuk kimia yang berkelanjutan, dan ketergantungan akan pasokan air [6].

\subsection{Aeroponik}

Aeroponik merupakan teknik penanaman hidroponik. Aeroponik berasal dari kata aero yang berarti udara dan ponus yang berarti daya, jadi aeroponik adalah sistem tanaman dengan memberdayakan udara dalam pemberian nutrisi ke tanaman. Cara kerja dari sistem Aeroponic yaitu larutan nutrisi diberikan ke tanaman dalam berupa kabut yang langsung menuju ke akar, sehingga tanaman lebih mudah menyerap nustrisi yang banyak mengandung oksigen. Sistem Aeroponik ini memungkinkan tanaman untuk bernafas dengan lancar dikarenakan akar dibiarkan dalam keadaan terbuka sehingga oksigen dapat dihirup oleh tanaman secara langsung. Dengan sistem aeroponik tanaman tidak rentan terkena hama, dan lebih mengemat air dan nutrisi [7].

\subsection{Sensor}

Sensor merupakan jenis transuder yang digunakan untuk mengubah besaran magnetis, panas, sinar, mekanis dan kimia menjadi besaran tegangan arus listrik yang dimanfaatkan untuk pembacaan nilai dari suatu benda atau kondisi. Sensor yang digunakan dalam penelitian sistem kontrol dan monitoring tanaman hidroponik aeroponic berbasis IoT yaitu sensor ultrasonik, dht22, ph, tds, dan water level.

Sensor ultrasonik adalah sensor yang digunakan untuk membaca jarak atau ketinggin dari suatu benda yang bekerja dengan bantuan gelombang suara. Sensor ini berfungsi untuk mengukur jarak dari suatu benda dengan frekuensi tertentu. Prinsip kerja sensor ultrasonik cukup sederhana yaitu pantulan gelombang ultrasonik mula-mula akan dipantulkan dan akan diterima kembali oleh unit sensor penerima yang menyebabkan diafragma pengetar akan bergerak dan menghasilkan efek tegangan bolak-balik dengan frekusensi yang sama [8].

Sensor dht22 adalah sensor yang dapat melakukan pengukuran suhu dan kelembapan yang memiliki jangkauan pengukuran $0-100 \%$ untuk tingkat kelembapan dan $-40^{\circ} \mathrm{C}$ hingga

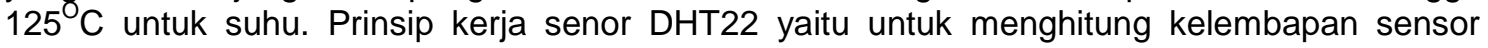
dht22 menggunakan komponen peraba kelembapan yang memiliki 2 elektroda yang dilengkapi pegangan substrat kelembapan diantara 2 elektroda, jadi ketika kelembapan dalam ruangan berubah maka konduktivitas antara substrat berubah. Sedangkan untuk suhu diukur menggunakan NTC (Negative Temperature Coefficient) atau thermistor (variable resistor yang merubah resistor dari temperature).

Sensor $\mathrm{pH}$ meter adalah sensor yang mengukur tingkat keasaman(asam) atau kebasaan(basa) dari suatu larutan/cairan. Prisnip kerja sensor $\mathrm{pH}$ yaitu berada pada sensor probe yang berupa elektroda kaca yang diisi dengan larutan HCL yang berada pada ujung sensor yang mengukur jumlah ion $\mathrm{H}_{3} \mathrm{O}^{+}$di dalam larutan [9].

Sensor TDS atau Total Dissolve Solid adalah sensor yang digunakan untuk mengkur konsentrasi massa kimiawai yang terlarut pada suatu zat, satuan yang digunakan yaitu part per million (ppm) atau milligram per liter (mg/l). Prinsip kerja dari sensor TDS meter yaitu menggunakan metode konduktivitas listrik yang memiliki kemampuan menghantarkan listrik yang berhubungan dengan kosentrasi padatan terlarut yang terionisasi di dalam air [10].

Sensor water level adalah sensor yang digunakan untuk mengukur ketinggian air. Prinsip kerja dari sensor water level adalah membaca resistensi air yang mengenai lempengan garus pada sensor, semakin tinggi kapasitas air yang mengenai lempengan maka nilai resitansinya semakin kecil begitu juga sebaliknya. 


\section{Hasil Dan Pembahasan}

Hasil dan pembahasan berisi tentang hasil dari perancangan perangkat dan analisa sistem yang dilakukan dalam penelitian ini.

\subsection{Perangkat Keras (Hardware)}

Rancang bangun dari perangkat keras yang digunakan dalam mengontrol dan memanajemen tanaman pada penelitian ini dapat dilihat pada Gambar 6 .

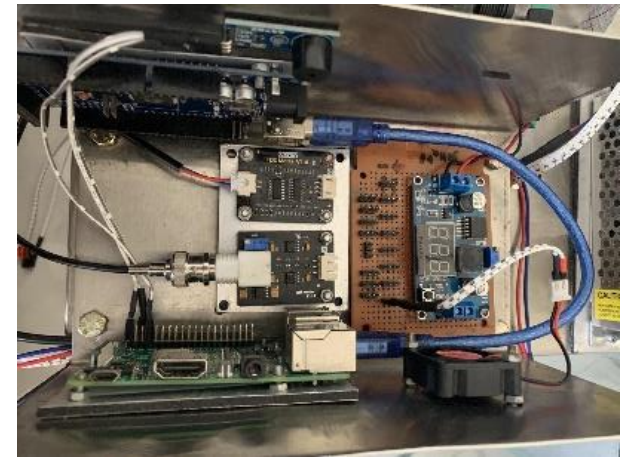

(a)

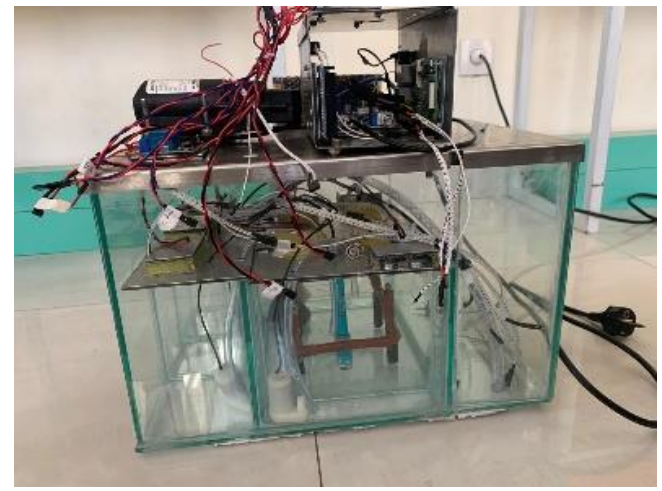

(c)

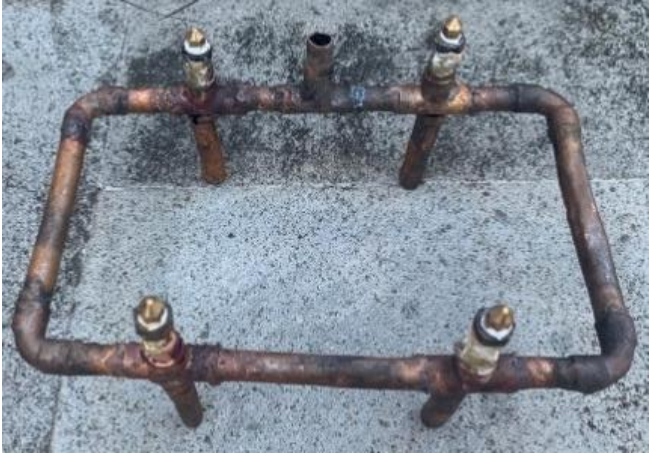

(b)

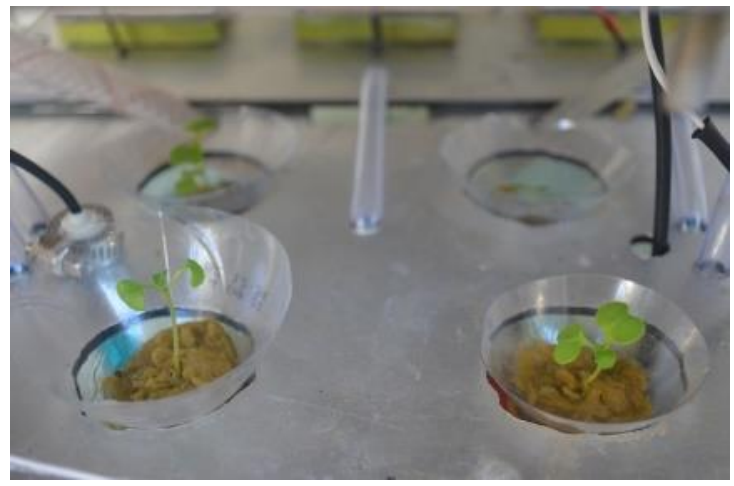

(d)

Gambar 6. Hasil rancangan perangkat keras

Hasil dari rancangan perangkat keras pada sistem meliputi (a) wadah manajemen perangkat loT digunakan sebagai tempat penyimpanan komponen perangkat loT seperti mikrokontroller dan beberapa sensor pendukung,(b) alat semprot tanaman digunakan sebagai pemberian nutrisi dalam bentuk kabut ke tanaman, (c) menampilkan keseluruhan dari rancangan perangkat dalam sistem tanam hidroponik aeroponik berbasis loT, dan (d) wadah tanaman digunakan sebagai tempat dalam melakukan penanaman tanaman hidroponik.

\subsection{Perangkat Lunak (Software)}

Aplikasi interface yang digunakan dalam controlling dan monitoring tanaman adalah aplikasi mobile berbasis android yang dapat dilihat pada Gambar 7 . 


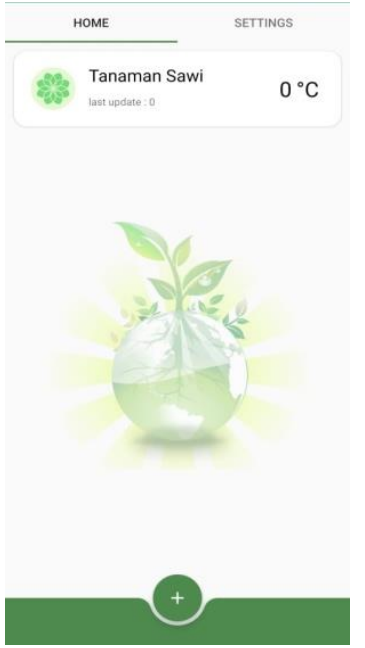

(a)

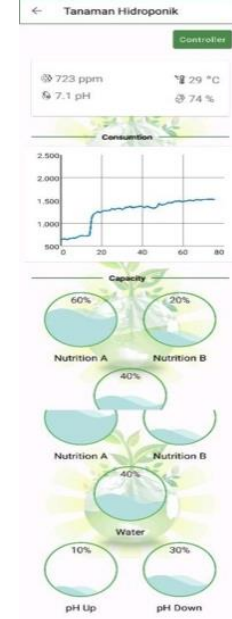

(b)

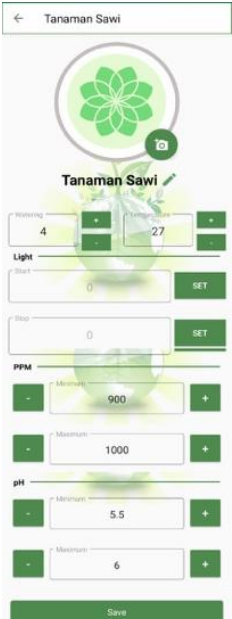

(c)

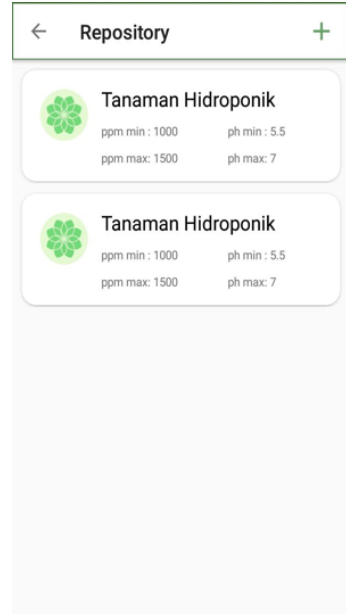

(d)

Gambar 7. Hasil rancangan perangkat lunak

Gambar di atas menampilkan hasil dari perancangan aplikasi android yang nantinya digunakan oleh pengguna dalam melakukan manajemen tanaman. (1) Pengguna mampu untuk menambah perangkat yang dimiliki, (2) monitoring kondisi perangkat, (3) controlling kebutuhan tanaman, dan (4) menyimpan setiap kondisi tanaman yang dimiliki agar dapat digunakan kembali.

\subsection{Uji Coba Dan Kalibrasi Sensor}

Uji coba dan kalibrasi sensor diperlukan untuk mengetahui seberapa akurat sensor dapat membaca nilai yang dihasilkan dengan menghitung Root Mean Square Error (RMSE) yang dihitung berdasarkan nilai didapatkan dan dibagi dengan jumlah sample data yang diambil, kemudian diakar kuadratkan sehingga mendapatkan nilai rata-rata kegagalan yang dihasilkan. Berikut pengujian dan kalibrasi sensor yang dilakukan.

\subsubsection{Hasil Uji Coba Dan Kalibrasi Sensor DHT22}

Pengujian sensor dht22 dengan thermometer digital dilakukan untuk mengetahui perbandingan nilai yang dihasilkan oleh sensor dht22 dengan thermometer digital. Hasil dari pengujian dapat dilihat pada Tabel 1 .

Tabel 1. Pengujian sensor dht22 dengan thermometer digital

\begin{tabular}{|c|c|c|c|c|}
\hline \multirow{2}{*}{$\begin{array}{c}\text { Pengujian } \\
\text { Ke - }\end{array}$} & \multicolumn{4}{|c|}{ Pengujian Sensor DHT22 $\left({ }^{\circ} \mathrm{C}\right)$} \\
\hline & Sensor DHT22 & Termometer & Error & $\begin{array}{l}\text { Square } \\
\text { Error }\end{array}$ \\
\hline 1 & 28.0 & 28.0 & 0 & 0 \\
\hline 2 & 27.8 & 27.7 & 0.1 & 0.01 \\
\hline 3 & 27.6 & 27.7 & -0.1 & 0.01 \\
\hline 4 & 27.7 & 27.9 & 0.2 & 0.04 \\
\hline 5 & 27.8 & 27.9 & -0.1 & 0.01 \\
\hline 6 & 27.8 & 27.8 & 0 & 0 \\
\hline 7 & 28.0 & 27.8 & 0.2 & 0.04 \\
\hline 8 & 27.7 & 28.0 &.-0.3 & 0.09 \\
\hline 9 & 27.6 & 27.6 & 0 & 0 \\
\hline 10 & 27.7 & 27.7 & 0 & 0 \\
\hline \multirow{2}{*}{\multicolumn{4}{|c|}{$\begin{array}{c}\text { Jumlah Square Error } \\
\text { Jumlah Data }\end{array}$}} & 0.20 \\
\hline \multicolumn{2}{|c|}{$\begin{array}{l}\text { Jumlah Data } \\
\text { Sorared Frror (RMSE) }\end{array}$} & & & 10 \\
\hline \multicolumn{4}{|c|}{ Root Mean Squared Error (RMSE) } & 0.14 \\
\hline
\end{tabular}


Pengujian perbandingan dilakukan pada ruangan yang tertutup sehingga nilai yang didapatkan lebih akurat. Hasil dari pengujian yang dilakukan didapatkan bahwa nilai yang dihasilkan oleh sensor dht22 lebih mengarah ke nilai yang lebih besar $(+)$ dibandingkan nilai yang dihasilkan oleh thermometer digital. Perbandingan yang dihasilkan mendapatkan nilai rata-rata kegagalan atau Root Mean Squared Error (RSME) sebesar 0.14 yang berarti nilai perkiraan hampir mendekati dengan nilai aslinya.

\subsubsection{Hasil Uji Coba Dan Kalibrasi Sensor Ultrasonik}

Pengujian sensor ultrasonik dengan penggaris dilakukan untuk mengetahui perbandingan nilai yang dihasilkan oleh sensor ultrasonik dengan penggaris. Hasil dari pengujian dapat dilihat pada Tabel 2 .

Tabel 2. Pengujian sensor ultrasonik dengan penggaris

\begin{tabular}{ccccc}
\hline $\begin{array}{c}\text { Pengujian } \\
\text { Ke }-\end{array}$ & $\begin{array}{c}\text { Sensor } \\
\text { Ultrasonik } \\
\text { HC-SR04 }\end{array}$ & $\begin{array}{c}\text { Pengujian Sensor Ultrasonik (cm) } \\
\text { Penggaris }\end{array}$ & $\begin{array}{c}\text { Error } \\
\text { Equare } \\
\text { Error }\end{array}$ \\
\hline 1 & 15.0 & 14.6 & 0.4 & 0.16 \\
\hline 2 & 14.6 & 14.6 & 0 & 0 \\
\hline 3 & 15.0 & 14.6 & 0.4 & 0.16 \\
\hline 4 & 14.6 & 14.6 & 0 & 0 \\
\hline 5 & 14.6 & 14.6 & 0 & 0 \\
\hline 6 & 14.6 & 14.6 & 0.4 & 0 \\
\hline 7 & 15.0 & 14.6 & 0 & 0.16 \\
\hline 8 & 14.6 & 14.6 & 0 & 0 \\
\hline 9 & 14.6 & 14.6 & 0.4 & 0 \\
\hline 10 & 14.6 & 14.6 & 0 & 0 \\
\hline \multicolumn{5}{c}{ Jumlah Square Error } \\
\hline
\end{tabular}

Pengujian perbandingan dilakukan pada media yang memiliki permukaan datar sehingga nilai yang dihasilkan lebih konstan. Hasil dari pengujian didapatkan bahwa nilai yang dihasilkan sensor ultrasonik mengarah ke lebih besar $(+)$ dari nilai yang didapatkan menggunakan alat ukur penggaris. Hal ini memungkinkan kesalahan pembacaan nilai pada sensor dapat terjadi sehingga didapatkan hasil yang kurang akurat dibandingkan menggunakan alat ukur penggaris. Terdapat perbedaan yang cukup terlihat tetapi tidak signifikan antara sensor ultrasonik dengan penggaris, dari hasil pengujian yang dilakukan sebanyak sepuluh kali percobaan didapatkan Root Mean Squared Error (RSME) sebesar 0.25 yang artinya nilai perkiraan tidak menjauhi nilai aslinya.

\subsubsection{Hasil Uji Coba Dan Kalibrasi Sensor pH}

Pengujian sensor ph dengan ph meter dilakukan untuk mengetahui perbandingan nilai yang dihasilkan oleh sensor ph dengan ph meter. Hasil dari pengujian dapat dilihat pada Tabel 3.

Tabel 3. Pengujian sensor ph dengan ph meter

\begin{tabular}{ccccccc}
\hline $\begin{array}{c}\text { Pengujian } \\
\text { Ke }-\end{array}$ & \multicolumn{7}{c}{$\begin{array}{c}\text { Pengujian Sensor pH dengan media air sabun (basa) } \\
\text { Sensor } \\
\text { WH }\end{array}$} & $\begin{array}{c}\text { Waktu Sensor } \\
\mathrm{pH}(\mathrm{s})\end{array}$ & $\begin{array}{c}\mathrm{pH} \\
\text { meter }\end{array}$ & $\begin{array}{c}\text { Whaktu } \\
\mathrm{pH} \text { meter (s) }\end{array}$ & Error & $\begin{array}{c}\text { Square } \\
\text { Error }\end{array}$ \\
\hline 1 & 7.8 & 4 & 7.7 & 3 & 0.1 & 0.01 \\
\hline 2 & 7.8 & 7 & 7.7 & 3 & 0.1 & 0.01 \\
\hline 3 & 7.7 & 7 & 7.7 & 3 & 0 & 0 \\
\hline 4 & 7.9 & 6 & 7.7 & 2 & 0.2 & 0.04 \\
\hline 5 & 7.6 & 6 & 7.7 & 2 & -0.1 & 0.01 \\
\hline
\end{tabular}




\begin{tabular}{|c|c|c|c|c|c|c|}
\hline 6 & 7.8 & 3 & 7.8 & 3 & 0 & 0 \\
\hline 7 & 7.7 & 2 & 7.8 & 2 & -0.1 & 0.01 \\
\hline 8 & 7.6 & 2 & 7.6 & 4 & 0 & 0 \\
\hline 9 & 7.7 & 3 & 7.7 & 3 & 0 & 0 \\
\hline 10 & 7.6 & 2 & 7.6 & 2 & 0 & 0 \\
\hline $\begin{array}{l}\text { Jumlah } \\
\text { Waktu }\end{array}$ & & & & 27 & $\begin{array}{c}\text { Jumlah Square } \\
\text { Error }\end{array}$ & 0.08 \\
\hline $\begin{array}{c}\text { Jumlah } \\
\text { Data }\end{array}$ & & & & 10 & Jumlah Data & 10 \\
\hline $\begin{array}{l}\text { Rata-rata } \\
\text { waktu }\end{array}$ & & & & 2.7 & $\begin{array}{l}\text { Root Mean } \\
\text { Squared Error }\end{array}$ & 0.089 \\
\hline
\end{tabular}

(RMSE)

Pengujian dilakukan menggunakan media air sabun sebagai indikator basa. Hasil dari pengujian didapatkan bahwa nilai yang dihasilkan oleh sensor ph lebih besar (+) dibandingkan dengan nilai yang dihasilkan oleh ph meter. Perbandingan nilai yang dihasilkan tidak begitu besar perbandingannya, hal itu dapat dilihat pada nilai Root Mean Squared Error (RMSE) sebesar 0.089 yang artinya jumlah perkiraan tidak menjauhi nilai aslinya dan rata-rata waktu yang dibutuhkan dalam pembacaan nilai ph yang terkandung yaitu sebesar 4.2 detik untuk sensor ph dan 2.7 detik untuk ph meter.

\subsubsection{Hasil Uji Coba Dan Kalibrasi Sensor TDS}

Pengujian sensor tds dengan tds meter dilakukan untuk mengetahui perbandingan nilai yang dihasilkan oleh sensor tds dengan tds meter. Hasil dari pengujian dapat dilihat pada Tabel 4.

Tabel 4. Pengujian sensor tds dengan tds meter

\begin{tabular}{cccccc}
\hline $\begin{array}{c}\text { Pengujian } \\
\text { Ke }-\end{array}$ & $\begin{array}{c}\text { Sensor } \\
\text { TDS }\end{array}$ & TDS meter & Larutan & Error & $\begin{array}{c}\text { Square } \\
\text { Error }\end{array}$ \\
\cline { 2 - 6 } & 212 & 213 & Mineral & -1 & 1 \\
\hline 2 & 621 & 636 & Garam & -15 & 225 \\
\hline 3 & 998 & 1013 & Mix AB & -15 & 225 \\
\hline 4 & 179 & 193 & Mineral & -14 & 196 \\
\hline 5 & 556 & 574 & Garam & -18 & 324 \\
\hline 6 & 989 & 1008 & Mix AB & -19 & 361 \\
\hline 7 & 191 & 201 & Mineral & -10 & 100 \\
\hline 8 & 560 & 578 & Garam & -18 & 324 \\
\hline 9 & 990 & 997 & Mix AB & -7 & 49 \\
\hline 10 & 189 & 201 & Mineral & -12 & 144 \\
\hline \multicolumn{7}{c}{ Jumlah Square Error } \\
\hline \multicolumn{7}{c}{ Jumlah Data } \\
\hline
\end{tabular}

Pengujian yang didapat dengan menggunakan sensor tds dan tds meter sebagai perbandingan nilai yang dihasilkan dengan menggunakan media larutan mineral, garam, dan mix $A B$ sebagai perbandingan pembacaan nilai tds. Pembacaan nilai yang dihasilkan oleh sensor tds lebih mengarah ke arah kurang (-) dari nilai yang dihasilkan oleh tds meter, hal ini dari ketiga media yang digunakan yang mengalami persentase paling sedikit kegagalan adalah media larutan mineral hanya berkisaran $1-14 \mathrm{ppm}$. Dari keseluruhan pengujian didapatkan Root Mean Squaed Error (RMSE) sebesar 13.9\%. 


\subsubsection{Hasil Uji Coba Dan Kalibrasi Sensor Water Level}

Pengujian sensor water level dengan penggaris dilakukan untuk mengetahui perbandingan nilai yang dihasilkan oleh water level dengan penggaris. Hasil dari pengujian dapat dilihat pada Tabel 5.

Tabel 5. Pengujian sensor water level dengan penggaris

\begin{tabular}{|c|c|c|c|c|}
\hline \multirow{2}{*}{$\begin{array}{c}\text { Pengujian } \\
\mathrm{Ke}-\end{array}$} & \multicolumn{4}{|c|}{ Pengujian Sensor Water Level (cm) } \\
\hline & $\begin{array}{c}\text { Sensor } \\
\text { Water Level }\end{array}$ & Penggaris & Error & $\begin{array}{c}\text { Square } \\
\text { Error }\end{array}$ \\
\hline 1 & 2.55 & 2.50 & 0.05 & 0.0025 \\
\hline 2 & 2.55 & 2.50 & 0.05 & 0.0025 \\
\hline 3 & 2.56 & 2.50 & 0.06 & 0.0036 \\
\hline 4 & 2.55 & 2.50 & 0.05 & 0.0025 \\
\hline 5 & 2.62 & 2.50 & 0.12 & 0.0144 \\
\hline 6 & 2.53 & 2.50 & 0.03 & 0.0009 \\
\hline 7 & 2.57 & 2.50 & 0.07 & 0.0049 \\
\hline 8 & 2.57 & 2.50 & 0.07 & 0.0049 \\
\hline 9 & 2.57 & 2.50 & 0.07 & 0.0049 \\
\hline 10 & 2.59 & 2.50 & 0.09 & 0.0081 \\
\hline \multicolumn{4}{|c|}{ Jumlah Square Error } & 0.0492 \\
\hline \multicolumn{4}{|c|}{ Jumlah Data } & 10 \\
\hline \multicolumn{4}{|c|}{ Root Mean Squared Error (RMSE) } & 0.07 \\
\hline
\end{tabular}

Pengujian dilakukan dalam wadah berbentuk kotak yang diisi dengan air sebagai media pengujian. Hasil dari pengujian yang dilakukan yaitu nilai yang dihasilkan oleh sensor water level lebih mengarah ke nilai yang lebih besar (+) dibandingkan dengan menggunakan alat ukur penggaris. Nilai yang dihasilkan tidak terlalu terpaut jauh antara sensor water level dengan alat ukur penggaris. Hasil dari pengujian yang dilakukan sebanyak sepuluh kali didapatkan nilai rata-rata kegagalan atau Root Mean Squared Error (RSME) sebesar 0.07 yang berarti nilai perkiraan sangat mendekati dengan nilai aslinya.

\subsubsection{Hasil Uji Coba Otomatisasi Pencampuran Nutrisi}

Pengujian otomatisasi pencampuran nutrisi dilakukan untuk mengetahui seberapa besar perubahan nilai yang dihasilkan dari pencampuran nutrisi. Hasil dari pengujian dapat dilihat pada Tabel 6.

Table 6. Pengujian otomatisasi pencampuran nutrisi

\begin{tabular}{|c|c|c|c|c|c|c|}
\hline \multirow{3}{*}{$\begin{array}{c}\text { Pengujian } \\
\text { Ke - }\end{array}$} & \multicolumn{6}{|c|}{ Pengujian Otomatisasi Pencampuran Nutrisi } \\
\hline & \multirow{2}{*}{$\begin{array}{c}\text { Aktif } \\
\text { Pompa }\end{array}$} & \multicolumn{2}{|c|}{ Nilai pH } & \multirow{2}{*}{$\begin{array}{c}\text { Aktif } \\
\text { Pompa }\end{array}$} & \multicolumn{2}{|c|}{ Nilai tds } \\
\hline & & Sebelum & Sesudah & & Sebelum & Sesudah \\
\hline 1 & 0 & 6.85 & 6.86 & 2 & 278 & 1250 \\
\hline 2 & 1 & 5.5 & 6.72 & 2 & 523 & 1426 \\
\hline 3 & 1 & 8.2 & 7.10 & 0 & 1122 & 1118 \\
\hline 4 & 1 & 6.2 & 7.05 & 1 & 843 & 1282 \\
\hline
\end{tabular}

Hasil dari pengujian sistem otomatisasi dalam pemenuhan kebutuhan campuran nutrisi dilakukan dengan membaca nilai ph dan tds dari larutan. Pengujiannya dari sistem otomatisasi dalam pencampuran kebutuhan nutrisi dilakukan sebanyak 4 kali percobaan. Pengujian dilakukan dengan mengecek nilai ph dan tds dari larutan kemudian disesuaikan dengan ph dan ppm yang telah ditentukan sebelumnya sehingga didapatkan hasil seperti pada Tabel 6. Hasil yang didapatkan dalam pencampuran ph yaitu dalam 1 kali pompa ph up menyala akan menghasilkan nilai rata-rata perubahan sebesar 0.9 dan untuk pompa ph down sebesar 0.9. Sedangkan untuk hasil yang didapatkan dalam pencampuran ppm yaitu dalam 1 kali pompa menyala didapatkan peningkatan sebesar 500 ppm. 


\subsection{Analisa Hasil Uji Coba Pada Tanaman}

Pengujian dilakukan selama 20 hari pada tanaman sawi putih dengan melihat hasil pertumbuhannya mulai dari tinggi batang, lebar batang dan jumlah cabang. Rekaman pertumbuhan dilakukan setiap hari, berikut hasil dari pertumbuhan tanaman sawi putih.

Tabel 7. Rekaman hasil pertumbuhan tanaman hidroponik (sawi putih)

\begin{tabular}{|cccc|}
\hline $\begin{array}{c}\text { Hari } \\
\text { ke }\end{array}$ & \multicolumn{3}{c}{ Tanaman Hidroponik loT } \\
\hline 0 & Tinggi Batang (TB) & Lebar Batang (LB) & Jumlah Daun \\
\hline 1 & 0 & 0 & 0 \\
\hline 2 & 0.1 & 0.05 & 2 \\
\hline 3 & 0.3 & 0.1 & 2 \\
\hline 4 & 0.6 & 0.1 & 2 \\
\hline 5 & 1 & 0.1 & 2 \\
\hline 6 & 1.3 & 0.1 & 2 \\
\hline 7 & 1.7 & 0.1 & 2 \\
\hline 8 & 2.1 & 0.1 & 2 \\
\hline 9 & 2.3 & 0.1 & 3 \\
\hline 10 & 2.5 & 0.1 & 3 \\
\hline 11 & 2.8 & 0.1 & 4 \\
\hline 12 & 3 & 0.1 & 4 \\
\hline 13 & 3.1 & 0.1 & 4 \\
\hline 14 & 3.2 & 0.1 & 4 \\
\hline 15 & 3.4 & 0.1 & 4 \\
\hline 16 & 3.5 & 0.1 & 4 \\
\hline 17 & 3.5 & 0.1 & 5 \\
\hline 18 & 3.6 & 0.1 & 5 \\
\hline 19 & 3.7 & 0.1 & 6 \\
\hline 20 & 3.9 & 0.1 & 6 \\
\hline
\end{tabular}

Tabel 7 di atas merupakan rekaman hasil dari pertumbuhan tanaman sawi putih yang dilakukan selama kurang lebih 20 hari mulai dari penyemaian hingga perpindahan pada sistem tanam hidroponik berbasis loT. Penyemaian dilakukan kurang lebih selama 2 hari atau batang sudah mulai tumbuh ke permukaan (biru), selanjutnya dilakukan perpindahan ke dalam sistem. Dalam sistem hidroponik loT kebutuhan nutrisi di kontrol sedemikian rupa sesuai dengan kebutuhan tanaman, pada tanaman berusia $3-9$ hari diberikan nutrisi 500 hingga $800 \mathrm{ppm}$ dalam sekali penyiramannya (kuning), dan pada saat usia tanaman 10 - dst diberikan nutrisi sebesar 1000 hingga 1500 ppm dalam sekali penyiraman (hijau). Suhu yang digunakan yaitu suhu ruangan diantara 26 sampai $32^{\circ} \mathrm{C}$ [3]. Pertumbuhan tanaman hidropok sawi putih berbasis loT didapatkan hasil seperti pada Gambar 8 di bawah ini.

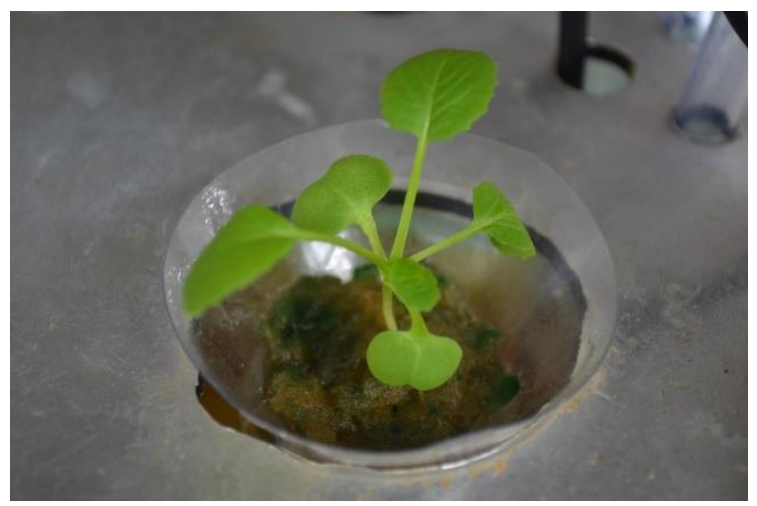

Gambar 8. Hasil pertumbuhan tanaman hidroponik (sawi putih) 
Dalam serangkain pengujian yang dilakukan didapatkan hasil, sistem telah mampu berjalan dengan sangat baik mulai dari controlling kebutuhan nutrisi, pencahayaan, penyiraman serta suhu dan kelembapan ruangan, sehingga kebutuhan yang diperlukan oleh tanaman dapat terpenuhi dan tumbuhan dapat tumbuh dengan cepat dan maksimal. Selain itu pengguna mampu dalam melakukan monitoring tanaman untuk mengecek setiap kondisi yang ada pada perangkat. Keberhasilan dalam penanaman tanaman hidroponik diakibatkan karena sistem telah dilakukan pengujian terlebih dahulu mulai dari kalibrasi sensor hingga pengujian keseluruhan sistem yang dilanjutkan ke implementasi sistem pada tanaman hidroponik. Kalibrasi sensor dilakukan untuk mengetahui tingkat keberhasilan nilai yang dihasilkan oleh sensor. Dalam pengujiannya sensor yang di uji coba adalah sensor ultrasonik digunakan untuk membaca ketinggian dari kapasitas campuran nutrisi yang ada pada wadah campuran nutrisi, sensor tds digunakan untuk pembacaan nilai konsentrasi larutan, sensor ph digunakan untuk membaca tingkat keasaman maupun kebasaan dari larutan, sensor dht22 digunakan untuk membaca suhu dan kelembapan ruangan, serta sensor water level untuk membaca ketinggian dari larutan.

\section{Kesimpulan}

Dari rancangan dan hasil uji coba dapat disimpulkan bahwa telah dihasilkan suatu rancangan sistem kontrol dan monitoring tanaman hidroponik aeroponik berbasis loT. Hal ini dibuktikan dengan rangkain uji coba seperti kalibrasi sensor, pengujian perangkat dan aplikasi android. Kesimpulan dari penelitian ini yaitu dalam uji coba pada sistem sudah dapat melakukan monitoring dan controlling tanaman, serta otomatisasi dalam pencampuran nutrisi sesuai dengan kebutuhan tanaman. Pengguna mampu untuk melakukan controlling setiap kondisi yang dibutuhkan tanaman seperti jumlah penyiraman, suhu, pencahayaan, batasan nilai tds, dan ph, serta pengguna dapat melakukan monitoring langsung dalam melakukan pengecekan kondisi yang ada pada perangkat dan juga jumlah nutrisi yang diberikan pada tanaman setiap penyiraman. Hasil yang didapat pada pengujian tanaman hidroponik yaitu tanaman dapat tumbuh dengan baik dalam perangkat loT yang dibuat.

\section{Daftar Pustaka}

[1] Prasetyo H. Industri 4.0: Telaah Klasifikasi Aspek Dan Arah Perkembangan Riset, Jurnal Teknik Industri. 2018;13.

[2] Crisnapati N, Wardana K, Aryanto A, Hermawan A, Hydroponic management and monitoring system for an IOT based NFT farm using web technology. ResearcGate. 2017:1-6.

[3] Subandi A, Widodo M. Rancang Bangun Sistem Aeroponik Secara Otomatis Berbasis Mikrokontroler. Jurnal Seminar Nasional Inovasi Dan Aplikasi Teknologi di Industri. 2016.

[4] Jayawiguna P. Rancangan Bangun Sistem Tanam Hidroponik NFT (Nutrient Film Technique) Berbasis Teknoilogi Internet of Things. Badung: Universitas Udayana. 2018.

[5] Junaidi A. Internet Of Things, Sejarah, Teknologi dan Penerapannya. Jurnal IImiah Teknologi Informasi Terapan. 2015;1.

[6] Suryani R. Hidroponik Budi Daya Tanaman Tanpa Tanah. Yogyakarta: ARCITRA. 2019: 82-87.

[7] https://klinikhidroponik.com/, diakses pada tanggal 15 Maret 2020.

[8] Arasada B, Suprianto B. Aplikasi Sensor Ultrasonik Untuk Deteksi Posisi Jarak Pada Ruang Menggunakan Arduino Uno. Jurnal Teknik Elektro. 2017;6.

[9] Desmira, Aribowo D, Pratama R. Penerapan Sensor pH Pada Area Elektrolizer Di PT. SULFINDO ADIUSAHA. Jurnal PROSISKO. 2018;5.

[10] Cahyani H, Harmadi, Wildian. Pengembangan Alat Ukur Total Dissolved Solid (TDS) Berbasis Mikrokontroler Dengan Beberapa Variasi Bentuk Sensor Konduktivitas. Jurnal Fisika Unand. 2016;5. 